\title{
Ocular reaction to timolol maleate
}

\author{
M. A. Frais \\ M.B., M.R.C.P. (U.K.)
}

T. J. BAYLEY

M.D., F.R.C.P.

Broadgreen General Hospital, Thomas Lane, Liverpool L14 3LB

\begin{abstract}
Summary
A patient prescribed timolol maleate for the control of hypertension developed dryness of the eyes. The symptoms improved on withdrawal of the drug.

Vigilance for such adverse reactions must be observed in the use of any $\beta$-adrenoreceptor blocking agent.

\section{Introduction}

Adverse reactions affecting the eyes have been described with several $\beta$-adrenoreceptor blocking agents, principally practolol. Both propranolol and oxprenolol have been incriminated in causing ocular symptoms but there are no reported instances of ocular damage due to timolol. The patient reported here developed dryness of the eyes, which improved subjectively on withdrawal of timolol.
\end{abstract}

\section{Case report}

A 40-year-old Caucasian fireman was discovered to have raised blood pressure on medical examination to assess fitness for use of breathing apparatus. He had no symptoms, nor had he suffered serious ill health in the past. Examination and investigation did not show any underlying cause for his hypertension. He was treated with chlorthalidone $100 \mathrm{mg}$ daily and timolol in doses of from 15 to $75 \mathrm{mg}$ daily, the BP falling satisfactorily from $180 / 130$ to $120 / 95$ $\mathrm{mmHg}$.

He first complained of dryness of the eyes and nose 14 months after starting treatment with timolol and later said that he had noticed his eyes had been dry and tender since starting the treatment. Examination showed poor tear production with punctate corneal staining after flourescein. Some areas of the bulbar and palpebral conjunctivae were noted as staining with Rose Bengal.

His symptoms improved immediately on withdrawal of timolol. When seen again 3 months later the bulbar conjunctival staining with Rose Bengal had cleared all but for the slightest staining in the left eye. Schirmer's test still showed poor tear production in both eyes. The raised BP was subsequently controlled with chlorthalidone $50 \mathrm{mg}$ and labetalol $600 \mathrm{mg}$ daily.

\section{Comment}

The adverse effects of practolol on the eyes were 8 first described 4 years after the introduction of the 3 . drug, as were the cutaneous manifestations of hyper- of sensitivity (Wright, 1974; Felix, Ive and Dahl, 1974). के Holt and Waddington (1975) reported an oculo- $O$ O cutaneous reaction to oxprenolol, and propranolol $\infty$ has been reported as causing an ocular reaction which $\$$ resolved on changing the $\beta$-blocker (Cubey and 윽 Taylor, 1975). Timolol has not been reported as producing such side effects, although there are single ${ }_{\mathbb{D}}$ reports to the Committee on Safety of Medicine $\underset{\mathbb{D}}{\mathbb{D}}$ (COSM) of morbilliform and psoriasiform rashes as well as exfoliative dermatitis.

The patient reported here developed irritatin dryness of the eyes and nose shortly after starting treatment with timolol. Conjunctival epithelial arfig corneal changes developed and there was a marked reduction in tear volume. Subjectively, he was improved on withdrawal of the drug. Objectively, tear $\overline{0}$ production was not improved but the epithelial changes had nearly resolved and the corneal abnor- $\unrhd$ malities were completely healed. Rahi et al. (1976) $\overrightarrow{\vec{O}}$ described a fibrosing polyserositis affecting the eyes, $\exists$ with acanthosis, and thickening of, and loss of goblet $\vec{F}$ cells from, the epithelium, and chronic inflammatory changes during treatment with $\beta$-blockers. The cornea $\bar{\partial}$ showed epitheliolysis and stromal ulceration, in- 3 . adequate tear production leading to epidermal- $\dot{\sigma}$ ization of the conjunctival epithelium-similar changes to those found in the present patient.

These changes have been found in association with an autoantibody with affinity for intercellular 음 zones of squamous epithelium. A significant in- $>$ crease in antinuclear antibody titre has been described in patients taking practolol, as well as thyroid $\bar{N}$ cytoplasmic antibody. These serological changes did ${ }^{\circ}$ not, however, correlate with the development of the $:$ oculo-cutaneous syndrome (Jachuck et al., 1977). In $\mathrm{N}^{\mathrm{\omega}}$ the present patient thyroglobulin antibody tests were negative as were flurescent antibody tests, althougho RA latex test was positive.

Although the ocular side effects described here are $\stackrel{\oplus}{+}$ not as well developed as those seen with practolol, $\underset{T}{0}$ the resemblance and the onset and partial clearing in 
relation to treatment with timolol suggest that the drug or a metabolite was responsible. In this patient there is no evidence that the adverse effects were of immunological cause. Such ocular damage may possibly occur with any of the $\beta$-adrenoreceptor blocking drugs. The absence of reports may be due to the failure of the patient to report and the doctor to enquire about symptoms, and the failure of doctors to notify the COSM.

\section{References}

CubeY, R.B. \& TAYLOR, S.H. (1975) Ocular reaction to propranolol and resolution on continued treatment with a different beta-blocking drug. British Medical Journal, 4, 327.

Felix, R.H., IVe, F.A. \& DAHL, M.G.C. (1974) Cutaneous and ocular reactions to practolol. British Medical Journal, 4, 321.

Holt, P.J.A. \& Waddington, E. (1975) Oculocutaneous reaction to oxprenolol. British Medical Journal, 2, 539.

JACHUCK, S.J., STEPHENSON, J., BiRD, T., JACKSON, F.S. \& Clark, F. (1977) Practolol-induced autoantibodies and their relation to oculo-cutaneous complications. Postgraduate Medical Journal, 53, 75.

Rahi, A.H.S., Chapman, C.M., Garner, A. \& Wright, P. (1976) Pathology of practolol-induced ocular toxicity. British Journal of Ophthalmology, 60, 312.

Wright, P. (1974) Skin reactions to practolol. British Medical Journal, 2, 560. 